\title{
A amizade para Foucault: RESISTÊNCIAS CRIATIVAS FACE AO BIOPODER ${ }^{\star}$
}

\author{
Hélio Rebello Cardoso $\mathrm{Jr}^{\star \star \star}$ \\ Thiago Canonenco Naldinho ${ }^{\star \star \star}$
}

\begin{abstract}
ReSUMO
O artigo trabalha a noção de amizade em Foucault como um modo de vida que se opõe ao processo de normalização empreendido pelo biopoder. Inicia com uma caracterização acerca do Estado Moderno. Logo após, aborda a historicidade dos processos de subjetivação e de como a atitude frente a estes implica estados de maior autonomia ou sujeição. Em seguida, aborda a amizade como resistência à normalização, situando-a em relação ao prazer e à sexualidade. Por fim, discute o papel da filosofia no processo de constituição da amizade, particularmente quanto à possibilidade de pensá-la por meio de uma teoria das relações.
\end{abstract}

Palavras-chave: Foucault; amizade; vida; existência; subjetivação.

\section{Friendship according to Foucault: CREATIVE RESISTANCE WITH REGARD TO BIOPOWER}

\begin{abstract}
This paper analyzes Foucault's concept of friendship both as relationship and way of living resistant to normalization promoted by biopower. We start by the description of the features which establish State as political form in its inner relations to biopower. Afterwards, we approach the historical profile of subjectivation processes and observe that the active or passive attitude with regard to them might accordingly determine the submission or autonomy of our subjectivity. In order to close, we discuss the importance of Philosophy to the establishment of friendship, with special regard to possibility of thinking with respect to a theory of relations.
\end{abstract}

Keywords: Foucault; friendship; life; existence; subjectivation.

\footnotetext{
$\star$ Fonte de financiamento: FAPESP

$\star \star$ Doutor em Filosofia pela Universidade Estadual de Campinas. Professor de Filosofia da Universidade Estadual Paulista Júlio de Mesquita Filho, Faculdade de Ciências e Letras de Assis, Departamento de História. Endereço: Av. Dom Antônio, 2001. CEP: 19806-173 - Assis, SP - Brasil. E-mail: herebell@hotmail.com

$\star \star \star$ Bacharelado, Licenciatura e Formação Clínica em Psicologia - Universidade Estadual Paulista/Assis. E-mail: thiago@kanonenko.com.br
} 


\section{Poder, SubjetivaÇão E Amizade}

Segundo Foucault (1995a, p. 236-239), no decorrer do século XVI surge uma nova forma política de poder, em constante desenvolvimento até hoje, chamada de Estado. Este tipo específico de poder não é mais permeado pela idéia de que seu fim seria a felicidade da população que governa; nem tampouco a relação entre o governante, seu território e seu povo; mas antes por uma nova forma de racionalidade intitulada "razão de Estado". Desde então, a finalidade do governo volta-se para o próprio Estado: sua manutenção, desenvolvimento e consolidação (FOUCAULT, 2005a, p. 304-306).

Dentro dessa dinâmica administrativa, o Estado Moderno Ocidental dispôs de um conjunto bem específico de técnicas de governo chamado de polícia que tinha por finalidade auxiliar no gerenciamento dos recursos disponíveis. Tal tecnologia cuidava praticamente de tudo relacionado à vida daqueles que constituíam a população governada: religião; moralidade; saúde; abastecimento; ruas, pontes, calçadas e edifícios públicos; segurança pública; artes liberais (artes e ciências); comércio; fábricas; empregados domésticos e carregadores; pobres; etc. (FOUCAULT, 2005a, p. 312). Todavia, esta preocupação com a vida dos indivíduos não se dava, como dissemos, com a finalidade da atingir a felicidade destes, mas especificamente com o objetivo de "aumentar permanentemente a produção de alguma coisa nova, considerada como podendo consolidar a vida cívica e o poderio do Estado" (FOUCAULT, 2005a, p. 315).

Não se tratava de uma ação solidária ou virtuosa, mas de uma estratégia enfocada na elaboração de saberes sobre o homem, a qual era subdividida em dois pólos: um quantitativo e globalizador, referente à população; e outro, analítico, referente ao indivíduo (FOUCAULT, 1995a, p. 238). O primeiro destinava-se a tratar das questões de larga escala, concernentes à administração das relações recíprocas e vivas entre os elementos físicos e econômicos do Estado e a população. Quanto ao aspecto analítico, o Estado visava descobrir e catalogar, também com fins administrativos, as necessidades e os gestos mais ínfimos do cotidiano das pessoas.

Um murmúrio que não cessará começa a se elevar: aquele através do qual as variações individuais de conduta, as vergonhas e os segredos são oferecidos pelo discurso para as tomadas do poder. [...] Todas essas coisas que compõem o comum [...] se tornaram descritíveis e passíveis de transcrição, na própria medida em que foram atravessadas pelos mecanismos de um poder político (FOUCAULT, 2003, p. 216).

Desse olhar minuciosamente normativo desenvolveram-se saberes relacionados tanto às ciências sociais e humanas quanto à medicina e à literatura, os quais contribuíram cada vez mais para a crescente intervenção do Estado na vida dos indivíduos (FOUCAULT, 2003, 2005a). Com efeito, toda a Episteme dessa época se estabelece a partir de um diagrama de poder que revela a origem das ciências cujo objeto é o homem. 
De tal modo, é por isso que se pode dizer que essa forma tão característica de racionalidade política surgida no século XVI, permeada pela idéia da razão de Estado, é relativa a um poder constituído por uma astuciosa combinação - desenvolvida a partir de uma antiga tecnologia de poder pastoral - de técnicas de individualização e de procedimentos de totalização. Essa forma de poder não ignorou a existência dos indivíduos em favor da população em geral, mas sim, concomitantemente à atenção dirigida a esta última, trabalhou arduamente na preservação e no estudo da vida dos indivíduos com a condição de que cada um destes fosse submetido a um conjunto de modelos muito específicos (FOUCAULT, 1995a, p. 236-237). Em particular, a racionalidade política do Estado, em sua forma analítica, ou seja, na medida em que se aplica ao indivíduo, engloba e redireciona uma antiga figura dos modos de subjetivação, característica do Cristianismo. Trata-se do poder pastoral, isto é daquele processo de subjetivação pelo qual o indivíduo encontra a verdade sobre si mesmo através de um minucioso exame de sua consciência. $\mathrm{O}$ poder pastoral pressupõe a existência, virtual ou atual, de um pastor ou diretor de consciência perante o qual o auto-exame de consciência é feito. Por isso, o mecanismo característico desse poder é a confissão, a qual será re-funcionalizada através do poder analítico do Estado.

Tendo tudo isto em vista, retornando à atualidade, podemos ainda observar a presença de tal racionalidade política atuando, sempre visando a preservação e o fortalecimento dessa forma de poder, como "matriz moderna da individualização" - impondo uma individualidade padronizada, da qual decorre, conseqüentemente, certo empobrecimento no desenvolvimento de relações entre as pessoas.

Vivemos em um mundo relacional consideravelmente empobrecido pelas instituições. A sociedade e as instituições que constituem sua ossatura limitaram a possibilidade de relações, porque um mundo relacional rico seria extremamente complicado de administrar (FOUCAULT, 2004a, p. 120).

O homem, sob esse ponto de vista, estaria impedido de escapar às imposições de individualidade do regime de saber, tornando-se sujeito apenas através de processos de sujeição. Estaria, desse modo, sob o jugo de um "governo da individualização" (FOUCAULT,1995a, p. 235-237).

Para Foucault, não podemos aceitar tal estado de submissão, pelo contrário, "devemos lutar contra esse empobrecimento do tecido relacional" (FOUCAULT, 2004a, p. 120). A estratégia para tanto encontrar-se-ia precisamente na relação que o indivíduo mantém consigo mesmo. "[...] não há outro ponto, primeiro e último, de resistência ao poder político senão na relação de si para consigo" (FOUCAULT, 2004 b, p. 306). Trata-se de uma conversão do poder. É a linha do poder que ao ser dobrada constitui um dentro, um forro, e é este espaço que o homem habita; proporcionando assim uma "relação da força consigo, um poder de se afetar a si mesmo, um afeto de si por si” (DELEUZE, 1988, p. 108). Esta dobra, inventada pelos antigos gregos, não deve ser compreendida apenas como uma forma de defesa, mas como condição de resistência ofensiva, de enfrentamento, ao poder. 
Os modos pelos quais nos tornamos sujeitos, os modos de "subjetivação", aparecem e se desenvolvem historicamente como "práticas de si" que, embora vigorem dentro de práticas discursivas (saberes) e práticas de poder que testemunham pela descontinuidade de suas formas históricas (FOUCAULT, 1984a, p. 23), correspondem, no campo específico da sexualidade ou aphrodisia 1 , a quatro grandes focos de "problematizações", a saber, "natureza do ato sexual, fidelidade monogâmica, relações homossexuais, castidade" (FOUCAULT, 1984a, p. 17), as quais atravessam as pretensas oposições entre a "filosofia pagã", a "ética cristã" e a "moral das sociedades européias modernas" (FOUCAULT, 1984a, p. 18).

A subjetividade, o sujeito, para Foucault, envolve um processo de subjetivação, visto que, segundo suas próprias palavras, não existe "constituição do sujeito moral sem modos de subjetivação" (FOUCAULT, 1984a, p. 28), ou seja, toda experiência que concretiza uma subjetividade envolve modos historicamente peculiares de se fazer a experiência do si (subjetivação). Toda subjetividade expressa algo de impessoal porque supõe processos de subjetivação onde se dá a "repartição de singularidades" de que fala Deleuze (1988). Assim, para valermonos da precisa terminologia deleuzeana, a subjetividade é um "efeito massivo" que provém de um processo singular. Os saberes e os poderes de todos os tempos procuram domar os processos de subjetivação, mas estes lhes escapam perfazendo uma história da resistência relativa à vida, pois "o ponto mais intenso das vidas, aquele em que se concentra sua energia, é bem ali onde elas se chocam com o poder, se debatem com ele, tentam utilizar suas forças ou escapar de suas armadilhas" (FOUCAULT, 2003, p. 208).

De modo que, de maneira semelhante aos antigos gregos, ${ }^{2}$ seria legítimo supormos que o indivíduo moderno através do governo de si poderia impor uma resistência ativa e direcionada contra a dominação imposta pelo biopoder. Tal resistência mostra-se presente nas lutas existentes desde o surgimento do Estado Moderno que colocam em questão o estatuto do indivíduo e se propõem não tanto atacar uma instituição, classe ou grupo em específico, mas antes essa precisa forma de poder que "categoriza o indivíduo, marca-o com sua própria individualidade, liga-o à sua própria identidade, impõe-lhe uma lei de verdade, que devemos reconhecer e que os outros têm que reconhecer nele [...]" (FOUCAULT, 1995a, p. 235). Contudo, mesmo sabendo que cada um pode infligir, através da relação que mantém consigo mesmo, uma potente resistência a essa forma política de poder que nos sujeita, como poderíamos ingressar efetivamente em tais lutas?

Segundo Foucault, a batalha contra o governo da individualização se daria através da "recusa deste tipo de individualidade que nos foi imposta há vários séculos" (FOUCAULT, 1995a, p. 239), seguida pela intensificação da imaginação e criação de novas formas de vida. O que sugere a necessidade de uma reabilitação da estética da existência na atualidade, a qual poderia proporcionar ao indivíduo, por meio de um trabalho realizado na própria relação consigo - uma ascese -, transformar sua maneira de pensar e realizar em si uma forma de vida inédita. 
Se me interessei pela Antiguidade foi porque, por toda uma série de razões, a idéia de uma moral como obediência a um código de regras está desaparecendo, já desapareceu. E a esta ausência de moral corresponde, deve corresponder uma busca que é aquela de uma "estética da existência”" (FOUCAULT, 2004c, p. 290, grifo nosso).

É nesse ponto que surge a importância da homossexualidade para tal intento, a qual foi para Foucault um campo privilegiado de estudo e experimentação para seu pensamento - devendo ser considerada não como uma forma de desejo, mas como algo desejável. A homossexualidade seria, então, em nosso tempo, uma dessas relações que escaparia ao biopoder subjetivante e acarretaria um enriquecimento do tecido relacional, isto é, através de problematizações que indicariam novos modos de vida.

É preciso que se troque a idéia que diz que devemos tentar re-introduzir a homossexualidade na normalidade geral das relações sociais, pela idéia de que devemos incentivar e permitir que a homossexualidade fuja dos tipos de relações que nos são propostos e impostos por nossa sociedade (FOUCAULT, 2004a, p. 122).

A homossexualidade é uma ocasião histórica de "reabrir virtualidades relacionais e afetivas", não tanto pelas qualidades intrínsecas do homossexual, mas pela "posição de 'enviesado", em qualquer forma, as linhas diagonais que se podem traçar "no tecido social", as quais permitem fazer aparecer essas virtualidades (FOUCAULT, 1981, online, grifo nosso).

Assim, em vez de os homossexuais procurarem em si a verdade ou o segredo íntimo de seu sexo, deveriam buscar usar do imenso potencial criativo de sua sexualidade, assim como de seu específico posicionamento ético-político - decorrentes da ausência de um sistema relacional - para desenvolverem múltiplas relações (FOUCAULT, 1981).

Desse modo, a questão atual para os homossexuais não seria apenas lutar pelo reconhecimento social e jurídico, manifestado pela busca de igualdade nos direitos individuais correntes entre os heterossexuais - casamento, adoção, herança, etc. -, mas, também, por um novo "direito relacional", ${ }^{3}$ o qual permitiria que todos os tipos de relação pudessem existir. Como Foucault (1984b) afirmou, os homossexuais não devem apenas se defender, porém também se afirmar e não somente enquanto identidades, mas prioritariamente enquanto força criativa. Tratase de reconhecer-se enquanto homossexual, isto é, atribuir-se o valor necessário e suficiente para realizar-se enquanto homossexual: buscar inventar e desenvolver, através de uma ascese contínua, um modo de vida gay, um tornar-se gay (FOUCAULT, 1981, 1984b, 2004a, p. 125). Em suma, para que a homossexualidade exerça e não perca seu caráter de inovação e resistência ao poder subjetivante moderno é preciso que suas lutas estratégicas não se limitem, como vimos, apenas às exigências por isonomia ou a uma identidade política, porém se prolonguem 
em uma constante "criação de novas formas de vida, de relações, de amizades nas sociedades, a arte, a cultura de novas formas que se instaurassem por meio de nossas escolhas sexuais, éticas e políticas" (FOUCAULT, 1984b, online).

Foi ao redor de toda essa discussão a respeito da homossexualidade, bem como da afirmação necessária de sua força produtora de subjetividades, que Foucault situou a questão da "amizade", todavia sem restringir, com isso, esta noção àquele campo específico. Segundo o autor, a homossexualidade se torna um problema social, político e médico, a partir do séc. XVIII, devido ao desaparecimento social da amizade entre os homens. Vale ressaltar que a amizade que Foucault trabalha difere quanto ao significado que a mesma possui atualmente. Tratava-se de uma relação social muito importante, desenvolvida nos séculos seguintes à Antigüidade, a qual permitia que em seu interior os indivíduos dispusessem "de uma certa liberdade, de uma certa forma de escolha (limitada, claramente), que lhes permitia também viver relações afetivas muito intensas" (FOUCAULT, 1984b, online). E este é o ponto de destaque, pois foi precisamente devido à existência e à produção dessa intensidade de afetos dentro da amizade que as instituições modernas viram a necessidade de extingui-la, ou pelo menos o seu caráter sexual, dos meios de intensa convivência entre homens, como, por exemplo, a escola e o exército.

Esse interesse foucaultiano pela amizade justifica-se pelo fato dos gays estarem buscando hoje em dia algo que possua certa relação com a homossexualidade, um estilo de vida. "Isso para onde caminha os desenvolvimentos do problema da homossexualidade é o problema da amizade" (FOUCAULT, 1981, online).

[...] o interesse pela amizade está se tornando muito importante. Não se entra simplesmente na relação para poder chegar à consumação sexual, o que se faz muito facilmente; mas aquilo para o que as pessoas são polarizadas é a "amizade". Como chegar, por meio das práticas sexuais, a um "sistema relacional"? "É possível criar um modo de vida homossexual?" [...] Um modo de vida pode ser partilhado por indivíduos de idade, estatuto e atividade sociais diferentes. Pode dar lugar a relações intensas que não se parecem com nenhuma daquelas que são institucionalizadas e me parece que "um modo de vida pode dar lugar a uma cultura e a uma ética" (FOUCAULT, 1981, online, grifo nosso).

É precisamente a ausência de um sistema relacional que faz da homossexualidade um campo fértil e aberto a novas possibilidades relacionais ainda não institucionalizadas. É por isso que Foucault vê com bons olhos a atual tarefa dos homossexuais, ou seja, "inventar de A a Z uma relação ainda sem forma que é a amizade: isto é, a soma de todas as coisas por meio das quais um e outro podem se dar prazer" (FOUCAULT, 1981, online).

É então que Foucault nos questiona a possibilidade de se criar, a partir da amizade - que é uma forma de relação, um modo de vida - uma ética, bem como uma cultura, ao redor do prazer. 
Somos capazes de ter uma ética dos atos e seus prazeres que possa levar em consideração o prazer do outro? O prazer do outro é algo que pode ser integrado ao nosso prazer, sem referência nem à lei, ao casamento, ou qualquer outra coisa? (FOUCAULT, 1995b, p. 258).

O prazer também deve fazer parte de nossa cultura. É muito interessante notar, por exemplo, que depois de séculos as pessoas em geral - mas também os médicos, os psiquiatras e mesmo os movimentos de liberação - têm sempre falado do desejo e nunca do prazer (FOUCAULT, 1984b, online).

Somos capazes de criar uma cultura no sentido amplo, isto é, inventar modalidades de relações, tipos de valores, formas de troca entre pessoas que sejam inéditas tendo em vista o prazer dos indivíduos? (FOUCAULT, 2004a, p. 122-123).

Digamos que "amizade" é, tão somente, a textura do "tecido relacional" de um tempo, em que pesem as capturas e as liberdades que nele encontramos. Por isso, temos de entender a amizade, em primeiro lugar, como o campo de relações em que nos constituímos, e que inclui, naturalmente, a amizade entre pessoas. De fato, qualquer relação determinada é uma amizade no sentido definido acima.

\section{TeOria das RELAÇões PARA A AMIZAde: PRAZER, DESSEXUALIZAÇÃo E ASCESE}

A questão que Foucault quer abordar a partir daí é a da necessidade de se criar uma nova vida cultural frente ao empobrecimento de nosso tecido relacional e afetivo; de se desenvolver produções culturais que tenham por objetivo principal o prazer; de produzir uma cultura de amizades a partir de um devirminoritário gay, a qual possibilite, mesmo parcialmente, que suas relações sejam transpostas aos heterossexuais, como a qualquer outra categoria (FOUCAULT, 1984b, 2004a, p. 122-123). Para tanto o trabalho não se destinaria às desgastadas lutas por liberação sexual, mas sim a um constante processo voluntário de reflexão e imaginação com a finalidade de nos constituirmos como seres mais suscetíveis, como também mais preocupados com o outro, no campo dos prazeres. Desse modo, em vez de tentarmos liberar o nosso desejo dos grilhões da repressão sexual, "[...] devemos criar prazeres novos. Então, pode ser que o desejo surja" (FOUCAULT, 1984b, online).

É importante assinalar que nessa relação entre amizade e prazer, Foucault encontra o sado-masoquismo como uma prática extremamente interessante e produtiva. Devido à rapidez e facilidade com que os homossexuais alcançam a consumação sexual, bem como à maior liberdade da qual dispõem, nesse campo, para a experimentação, surge o sado-masoquismo como uma linha de fuga ao caminho do tédio e da tristeza, trazendo consigo um intenso fator multiplicador de possibilidades de prazer.

Eu penso que temos uma forma de criação, de empreendimento de criatividade, dos quais a principal característica é o que chamo de "dessexualização do prazer". A idéia de que o 
prazer físico provém sempre do prazer sexual e a idéia de que o prazer sexual é a base de todos os prazeres possíveis, penso, é verdadeiramente algo de falso. O que essas práticas de S/ $\mathrm{M}$ nos mostram é que nós podemos produzir prazer a partir dos objetos mais estranhos, utilizando certas partes estranhas do corpo, nas situações mais inabituais, etc. (FOUCAULT, 1984b, online, grifo nosso).

O que se pode entender com esse processo de dessexualização do prazer é que a sexualidade, mesmo aparecendo constantemente como uma das fontes mais produtivas de nossa sociedade e de nosso ser, não deve ser entendida como uma fatalidade, mas antes como uma possibilidade de se alcançar uma vida criativa (FOUCAULT, 1984b). Com isso, Foucault liberta o prazer do campo normativo da sexualidade e lhe oferece uma abundância de possibilidades de surgimento através da criatividade de qualquer "prática possível".

Nesse campo suscetível ao surgimento de múltiplas relações inéditas, constituído pela amizade, a existência do poder é inevitável, pois, segundo Foucault, em qualquer relação humana há relações de poder, sendo que quanto mais aberto for o jogo maior será o desejo de determinar a conduta do outro (FOUCAULT, 2004d, p. 276-286). Convém destacar que esse governo da conduta alheia, enquanto relação de poder, não visa a destruição do outro, pelo contrário, considera-o como um sujeito ativo que tem sempre a possibilidade de fuga, resistência, luta e inversão da situação (FOUCAULT, 1995a, p. 243). Entretanto, há casos em que as relações de poder podem se tornar saturadas de tal forma que a mobilidade entre as estratégias desaparece:

Quando um indivíduo ou um grupo social chega a bloquear um campo de relações, a torná-las imóveis e fixas e a impedir qualquer reversibilidade do movimento - por instrumentos que tanto podem ser econômicos quanto políticos ou militares -, estamos diante do que se pode chamar de um "estado de dominação" (FOUCAULT, 2004d, p. 266, grifo nosso).

Toma destaque, então, a questão de como evitar que tais fatos de dominação apareçam na amizade. Como vimos, Foucault acredita que possa surgir uma ética a partir de um modo de vida, de maneira que, seguindo tal pensamento, seria lógico acreditarmos na existência, a partir da amizade, de éticas que levem em consideração o prazer alheio. Todavia, essa preocupação com a satisfação do outro seria um impeditivo suficientemente capaz de barrar o aparecimento de estados de dominação? A resposta para esse problema parece estar no modo como agimos dentro das relações de poder que experimentamos todos os dias, uma vez que, para Foucault, deveríamos agir de maneira bastante prudente e empírica, atentos a todos os detalhes, pois o que separa tais relações dos estados de dominação é uma linha extremamente emaranhada e nebulosa (FOUCAULT, 2004e, p. 223). Em adição a isso, caso sejam encontrados pontos de dominação, faz-se necessário ter sempre em mente um princípio crítico $^{4}$ que questione a necessidade, para a estratégia em questão, da existência de tais focos de não-consensualidade. 
É importante esclarecer que essa preocupação com a presença de focos de não-consensualidade, ou mesmo de dominação, não exclui da amizade a existência de conflitos, pelo contrário, estes são extremamente significativos para tal modo de vida. Nele, há um campo fecundo aos embates de idéias, os quais não buscam alcançar uma verdade universal, mas permitir a consideração de múltiplos pontos de vista com a finalidade de colher material a ser refletido e, posteriormente, utilizado na incessante criação do Si.

A amizade [...] [é] a afirmação de existências livres. Os amigos vivem pelas suas diferenças. Não são espelhos para os outros, identidade coletiva ou ideal, fusão numa unidade superior. Os amigos livres são seus principais inimigos, não deixam as coisas sossegadas, como se houvesse um patamar acima a ser atingido onde residem o equilíbrio, a doçura e as delicadezas obrigatórias (PASSETTI, 2003, p. 12).

Dessa maneira, o que se enfoca não é o apego a formas de identidade com características em comum, mas sim um esforço para a compreensão e aceitação do outro como diferença inquietante. Como sugere Nietzsche (2006, p. 56-57): "é preciso honrar no amigo o inimigo. [...] No amigo deve ver-se o melhor inimigo". Não se deve buscar encontrar no amigo um reforço para sua identidade, mas, pelo contrário, material para transformação e criação do Si.

Como pôde ser observado, toda a amizade foucaultiana é permeada por certo fator de conflito; de inovação, experimentação, diferenciação; de reflexão, trabalho e afirmação de si enquanto força criativa - ou seja, por uma certa atitude ativa frente às condições atuais em que vivemos. Essa postura não passiva, esse modo de ser encontrado na amizade, pode ser entendido como aquilo que Foucault chamava de "atitude de modernidade".

Por atitude, quero dizer um modo de relação que concerne à atualidade; uma escolha voluntária que é feita por alguns; enfim, uma maneira de pensar e de sentir, uma maneira também de agir e de se conduzir que, tudo ao mesmo tempo, marca uma pertinência e se apresenta como uma tarefa. Um pouco, sem dúvida, como aquilo que os gregos chamavam de êthos (FOUCAULT, 2005b, p. 341-342, grifo do autor).

Trata-se de certa maneira de se conduzir consistente em um permanente trabalho crítico sobre nossos próprios limites e que se dá através de uma ontologia crítica de nós mesmos, aliado a uma intensa experimentação.

Quero dizer que esse trabalho realizado nos limites de nós mesmos deve, por um lado, abrir um domínio de pesquisas históricas e, por outro, colocar-se à prova da realidade e da atualidade, para simultaneamente apreender os pontos em que a mudança é possível e desejável e para determinar a forma precisa a dar a essa mudança (FOUCAULT, 2005b, p. 348). 
Como ferramenta de extrema valia em tal processo, toma destaque o modo como Foucault considerava a Filosofia - "uma 'ascese', um exercício de si, no pensamento" (FOUCAULT, 1984a, p. 13). De fato, o pensador ligava as questões relativas à construção dos modos de vida, como o modo gay, a uma maneira prática de se entender a necessidade da filosofia:

[...] o que é filosofar hoje em dia - quero dizer, a atividade filosófica - senão o trabalho crítico do pensamento sobre o próprio pensamento? Se não consistir em tentar saber de que maneira e até onde seria possível pensar diferentemente em vez de legitimar o que já se sabe? (FOUCAULT, 1984a, p. 13).

Tal ponto de vista acerca da filosofia não é recente, tendo sido o mesmo corrente entre os antigos gregos, helenísticos e romanos, para os quais a filosofia significava um permanente exercício de transformação de si durante toda a vida daqueles que quisessem alcançar a verdade, bem como a única capaz de dirigir o pensamento (FOUCAULT, 1984a, 1985; ORTEGA, 1999).

Nessa ascese, o material a ser trabalhado, através de uma intensa atitude experimental, seria o pensamento.

A filosofia é o deslocamento e a transformação das molduras de pensamento, a modificação dos valores estabelecidos, e todo o trabalho que se faz para pensar diferentemente, para fazer diversamente, para "tornar-se outro do que se é" (FOUCAULT, 1994, p. 143, grifo nosso).

Evidencia-se, com isso, a importância que Foucault atribui ao pensamento no que tange à ascese, uma vez que esse se situaria como o principal instrumento-efeito do trabalho de si sobre si. Seria, através da filosofia que poderíamos confrontar o que somos e fazemos com o que pensamos e dizemos, refletir sobre aquilo que acreditamos, transformar nossos pensamentos, enfim: questionar e elaborar de forma diversa aquilo que somos. E é este o ponto que acreditamos ser o elo entre a estética da existência presente na Antiguidade e a amizade para Foucault - "a noção de filosofia como ascese interligada a sua noção de amizade".

Com efeito, podemos compreender tal afirmação seguindo um encadeamento lógico de algumas importantes considerações. Em primeiro lugar, Foucault acredita que a ética é uma prática, a "prática refletida da liberdade" (FOUCAULT, 2004d, p. 267); em segundo, que o modo como pensamos hoje em dia é influenciado por uma tradição de racionalidades que se coaduna ao biopoder e, por isso, a solução para questionarmos e modificarmos o regime de verdade de nossa época estaria no exercício "crítico e reflexivo" do pensamento sobre seus próprios parâmetros - tarefa da filosofia; e por fim, amarrando a linha de raciocínio, que há a necessidade de uma consonância entre atos e palavras, isto é, entre ética e política - o que explica a declaração de Foucault de que a chave da atitude política pessoal de um filósofo deva ser procurada em sua "filosofia como vida, em sua vida filosófica, em seu êthos" (FOUCAULT, 2004e, p. 219, grifo do autor) e 
não em suas idéias. Por tudo isso, torna-se evidente que a amizade foucaultiana utiliza-se da filosofia como um exercício de si no pensamento para constituir-se como um modo de vida e de relações que escapa constante dos processos de institucionalização e restrição do tecido relacional impostos pelo biopoder subjetivante. É devido a essa ascese filosófica do pensamento que a amizade exerce seu potencial de ruptura do instituído e de desenvolvimento de inéditas criações culturais com suas implicações ético-políticas. Enfim, vale ressaltar, mais uma vez, que todo esse processo expansivo e positivo efetuado pela amizade não se restringe ao campo homossexual masculino - o qual serviu de base de estudos e experimentação para a elaboração de tal conceito foucaultiano -, uma vez que essa pode surgir em qualquer segmento social que seja permeado pelas necessárias contingências sócio-histórico-políticas. De fato, na amizade, trata-se justamente do desenvolvimento de relações que ultrapassem quaisquer categorias, sejam elas de gênero, idade, classe social, etc., uma vez que é por meio da normalização e compartimentalização das relações que o biopoder restringe e captura os processos de subjetivação.

Com tudo isso, após seguirmos a empreitada foucaultiana direcionada à busca por modos de vida mais autônomos, podemos caracterizar a amizade como sendo uma forma de se relacionar, uma maneira ou estilo de ser e de se conduzir, buscada voluntariamente por alguns, que traz consigo um modo de pensar, sentir, agir que não menospreza a atualidade. Esse êthos filosófico busca constantemente analisar e refletir sobre os limites que determinam o que somos, pensamos e fazemos, ao mesmo tempo em que, permanentemente, experimenta o atual com o intuito de descobrir onde podem surgir os novos focos de processos de subjetivação. Sendo por isso que a amizade é considerada como uma estratégia de resistência extremamente perigosa para o biopoder subjetivante, uma vez que contradiz e combate diretamente a individualidade padronizada imposta por essa específica forma de poder.

$\mathrm{Na}$ amizade, através do elogio ao prazer, multiplicam-se os campos de possibilidade de relacionamentos e, conseqüentemente, de surgimento de novas subjetividades. A amizade, por isso, é a expansão das relações, de qualquer relação, para além de suas supostas codificações. Esse conceito de amizade não é muito difícil de realizar, porque o que mais há são as relações que não se enquadram. Elas são até mais numerosas de que as relações codificadas. O difícil é percebêlas, pois são mais provisórias do que as outras que julgamos a "verdadeira amizade". Provisórias, não no sentido de pouco duradouras; provisórias porque elas acontecem de costume num corpo a corpo com as outras, à sombra daquelas mais codificadas e estabelecidas.

Sendo o prazer a potência criativa, a "força do encontro que constitui o corpo de relações" (CARDOSO JR., 2005, p. 346) entre nosso núcleo de subjetividades e as coisas que nos circundam, fica clara a intenção foucaultiana ao situá-lo como ponto de materialização de uma cultura "por vir". Foucault via nessa cultura criativa, ainda por ser inventada, a saída para o "duplo constrangimento" 
- a simultânea individualização e totalização - político, ético, social e filosófico a que somos sujeitados pelo poder moderno. Uma cultura do prazer que traga consigo o gozo do possível.

Para terminar, faremos uma pergunta que dará a indicação para a continuidade possível do presente artigo: a preocupação de Foucault implica uma teoria das relações, um modo de pensar as relações tendo em vista as questões filosóficas apresentadas ao longo de nosso argumento?

Foucault e Deleuze impulsionaram uma "teoria das relações". Isto é, uma teoria cujos princípios são práticos, uma teoria voltada para a invenção de modos de vida, sem a qual nossa existência ética teria de se render aos valores estabelecidos.

De um ponto de vista mais estrito, levando-se em conta os processos de "subjetivação", ou seja, toda relação na qual nos colocamos como sujeitos, a teoria das relações adquire contornos mais significativos. Uma relação de amizade não se deve àquilo que deriva dos indivíduos envolvidos, mas dos feixes de relações que atravessam um e outro, relações de ordem biológica, social, econômica, histórica, etc. Tornarmo-nos sujeitos demanda, portanto, toda uma implicação de linhas que formam o tecido relacional, logo, em certo sentido, é correto dizer que as relações através das quais somos compostos, por exemplo, como amigos, são exteriores às duas pessoas que, por meio delas, se tornam amigas. Cada amizade, envolva ela um ou "n indivíduos", sempre traz consigo um emaranhado de mundos que não pertencem e nem podem ser controlados por nenhum dos envolvidos. Por isso, as relações são sempre exteriores aos termos que elas relacionam (DELEUZE, 1953, p. 109).

Mas, como relações podem ser exteriores e por que seu efeito pode ser a diferenciação ou criação de novos modos de vida?

Pode-se afirmar, aos nos referirmos a uma relação, que um terceiro indivíduo aparece. "Ele" tem vida própria, pois é exterior aos amigos dos quais provém, sendo que a amizade pode ser entendida como um novo "corpo" que se autopõe e que os amigos devem nutrir e manter. Esse terceiro é o corpo do "fora", ele não está entre os próprios elementos interligados, é a própria relação. Isso quer dizer, para reforçarmos uma idéia anteriormente enunciada, que o essencial de uma amizade, seu destino, depende dessa exterioridade, pois não pertence nem a um nem a outro dos amigos. A amizade sempre está "entre". 


\section{Notas}

${ }^{1}$ Os aphrodisia eram a dinâmica constituída pelos atos, prazeres e desejos relacionados à atividade sexual na Antigüidade greco-helenística-romana (Cf. FOUCAULT, 1995b, p. 263-266).

${ }^{2}$ Foucault não acreditava que deveríamos encontrar a solução para um problema atual em outras épocas. No entanto, pensava que o contato com outras experiências poderia nos servir de exemplo que a alternativa é possível (Cf. FOUCAULT, 2004d, p. 280).

${ }^{3}$ A luta por direitos empreendida pelas minorias era estimada por Foucault, todavia ele acreditava que essa seria apenas a primeira etapa na batalha contra a matriz moderna da individualização, pois uma outra dimensão importante estaria na possibilidade de criação que perpassa qualquer minoria, pelo fato destas estarem fora da abrangência do restrito sistema relacional imposto pelo poder subjetivante. Quanto ao direito relacional, podemos dizer que este não se restringe aos direitos associativos, os quais já foram conquistados no século XIX. "O direito relacional é a possibilidade de fazer reconhecer, em um campo institucional, relações de indivíduo para indivíduo que não passem necessariamente pela emergência de um grupo reconhecido. É algo completamente diferente [dos direitos associativos]. Trata-se de imaginar como a relação entre dois indivíduos pode ser validada pela sociedade e se beneficiar das mesmas vantagens que as relações - perfeitamente honrosas - que são as únicas a serem reconhecidas: as relações de casamento e de parentesco" (FOUCAULT, 2004a, p. 125).

${ }^{4}$ Foucault destaca a importância deste não ser um princípio regulador, mas crítico, o que parece sugerir a importância, por ele atribuída, de ser empírico ao se tratar de relações de poder : "Não diria princípio regulador, pois seria ir longe demais, porque, a partir do momento em que se diz princípio regulador, admite-se que é em função disso que o fato deve se organizar, dentro dos limites que podem ser definidos pela experiência ou pelo contexto. [...] talvez não se deva ser a favor da consensualidade, mas contra a não-consensualidade.” (FOUCAULT, 2004e, p. 224).

\section{REFERÊNCIAS}

CARDOSO JR., H. R. Para que serve uma subjetividade?: Foucault, tempo e corpo. Psicologia, reflexão e crítica. Porto Alegre, v. 18, n. 3, p. 343-349, 2005.

DELEUZE, G. Empirisme et Subjectivité. Paris: PUF, 1953.

. Foucault. São Paulo: Brasiliense, 1988.

FOUCAULT, M. De l'amitié comme mode de vie. Gai Pied, no 25, p. 38-39, abr. 1981. Disponível em: htttp://www.unb.br/fe/tef/filoesco/foucault._Acesso em: 10 nov. 2006. Entrevista de Michel Foucault a R. de Ceccaty, J. Danet e J. le Bitoux. Tradução de Wanderson Flor do Nascimento.

. História da sexualidade: o uso dos prazeres. Rio de Janeiro: Graal, 1984a. v. 2.

. Sex, power and the politics of identity. The Advocate, Los Angeles,

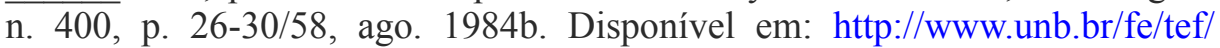
filoesco/foucault/sexpodident.html. Acesso em: 10 nov. 2006. Entrevista de Michel Foucault a B. Gallagher e A. Wilson. Tradução de Wanderson Flor do Nascimento.

. História da sexualidade: o cuidado de si. Rio de Janeiro: Graal, 1985. v. 3. .Archivio Foucault . Milano: Feltrinelli, 1994. v. 3: Estetica dell'esistenza - A cura di Alessandro Pandofi. 
FOUCAULT, M. O sujeito e o poder. In: RABINOW, P.; DREYFUS, H. (Org.). Michel Foucault, uma trajetória filosófica: para além do estruturalismo e da hermenêutica. Rio de Janeiro: Forense Universitária, 1995a. p. 231-249.

. Michel Foucault entrevistado por Hubert L. Dreyfus e Paul Rabinow. In: RABINOW, P.; DREYFUS, H. (Org.). Michel Foucault, uma trajetória filosófica: para além do estruturalismo e da hermenêutica. Rio de Janeiro: Forense Universitária, 1995b. p. 253-278.

. A vida dos homens infames. In: MOTTA, M. (Org.). Estratégia, PoderSaber. Rio de Janeiro: Forense Universitária, 2003. v. 4, p. 203-222. Coleção Ditos \& Escritos.

. O triunfo social do prazer sexual: uma conversação com Michel Foucault. In: MOTTA, M. (Org.). Ética, sexualidade e política. Rio de Janeiro: Forense Universitária, 2004a. v. 5, p. 119-125. Coleção Ditos \& Escritos.

. A hermenêutica do sujeito. São Paulo: Martins Fontes, 2004b.

. Uma estética da existência. In: MOTTA, M. (Org.). Ética, sexualidade e

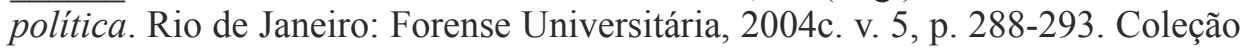
Ditos \& Escritos.

. A ética do cuidado de si como prática da liberdade. In: MOTTA, M. B. (Ed.). Etica, sexualidade e politica. Rio de Janeiro: Forense Universitária, 2004d. v. 5, p. 264-287. Coleção Ditos \& Escritos.

Política e ética: uma entrevista. In: MOTTA, M.(Org.). Ética, sexualidade e política. Rio de Janeiro: Forense Universitária, 2004e. v. 5, p. 218-224. Coleção Ditos \& Escritos.

. A tecnologia política dos indivíduos. In: MOTTA, M. (Org.). Arqueologia das ciências e história dos sistemas de pensamento. Rio de Janeiro: Forense Universitária, 2005a. v. 5, p. 301-318. Coleção Ditos \& Escritos.

O que são as luzes? In: MOTTA, M. (Org.). Arqueologia das ciências e história dos sistemas de pensamento. Rio de Janeiro: Forense Universitária, 2005b. v. 2, p. 335-366. Coleção Ditos \& Escritos.

NIETZSCHE, F. Assim falou Zaratustra. São Paulo: M. Claret, 2006. v. 22. Coleção a obra-prima de cada autor.

ORTEGA, F. Amizade e estética da existência em Foucault. Rio de Janeiro: Graal, 1999.

PASSETTI, E. Éticas dos amigos: invenções libertárias da vida. São Paulo: Imaginário, 2003.

Recebido em: maio de 2008

Aceito em: abril de 2009 